\title{
Use of Reverse Osmosis Reject Water for Value Addition in Coco Substrate Industry
}

\author{
J.A.M. Wijeratna, M.W. Jayaweera, J.M.A. Manatunge* , W.B. Gunawardana, A.A.S.U. \\ Gunarathna, M.I. Sudasinghe \\ Department of Civil Engineering, University of Moratuwa, Sri Lanka \\ *manatunge@gmail.com
}

\begin{abstract}
Previous studies corroborated that water enriched with various compounds is a major reason for Chronic Kidney Disease of Unknown Aetiology (CKDu) in Sri Lanka. Reverse osmosis (RO) units are being introduced in the $\mathrm{CKDu}$ prevalent areas for water purification. Generally, the RO reject water is disposed of directly to the ground and/or used for irrigation purposes because it contains several minerals, which are favourable for the growth of plants. However, this practice may cause any negative environmental issues.

Calcium nitrate is used as a value addition in coco substrate industry to wash out sodium from the coir products because sodium competes with other cations which are essential for plant growth in the process of adsorption. However, discharging the spent calcium nitrate solution to land for irrigation purposes may lead to nitrate pollution. This study investigates the possibility of using RO reject water, which has considerably high amounts of calcium, as an alternative for the use of calcium nitrate, which may also lead to reduction of cost of importing calcium nitrate. Leachability tests were carried out using husk chips as the solid medium with RO reject water and calcium nitrate as the treatment solution, respectively. When RO reject water was used as the washing solution, the results manifested (amount of calcium, magnesium adsorbed and sodium, potassium leached out) that the leachability potential was well within the acceptable range as per the protocols. Based on the findings, $\mathrm{RO}$ reject water could be proposed as an alternative source to calcium nitrate.
\end{abstract}

Keywords: Calcium nitrate, Coco substrate, Husk chips, Reverse osmosis, Water purification 